\title{
Dynamic crushing and energy absorption of sandwich structures with combined geometry shell cores
}

\author{
Alper Tasdemirci*, Ali Kara, Kivanc Turan, Selim Sahin \\ Dynamic Testing and Modeling Laboratory and Department of Mechanical Engineering, Izmir Institute of Technology, Gulbahce, Urla, Izmir, Turkey
}

\section{A R T I C L E I N F O}

\section{Article history:}

Received 17 October 2014

Received in revised form

6 January 2015

Accepted 16 February 2015

Available online 7 March 2015

\section{Keywords:}

Combined geometry shells

Sandwich structures

Crushing behavior

Energy absorbtion

Micro inertia

Finite element method

\begin{abstract}
A B S T R A C T
Dynamic crushing and energy absorption characteristics of sandwich structures with combined geometry shell cores were investigated experimentally and numerically. The effect of strain rate on the crushing behavior was presented by the crushing tests at quasi-static, intermediate and high strain rate regimes. It was shown that absorbed energy increased with increasing impact velocity. The effect of confinement on crushing behavior was shown by conducting confined experiments at quasi-static and dynamic rates. Higher buckling loads at lower deformation were observed in confined quasi-static crushing due to additional lateral support and friction provided by confinement wall. By using fictitious numerical models with strain rate insensitive material models, the effect of inertia and strain rate on crushing were shown. It was observed that, increase in impact velocity caused increase in inertial effects and strain rate effects were nearly independent from the impact velocity. The effects of multilayering were also investigated numerically.
\end{abstract}

(c) 2015 Elsevier Ltd. All rights reserved.

\section{Introduction}

Design of lightweight structures with high energy absorption capability is a major concern in automotive (dynamic crush resistance), aerospace (low weight), and military (impact and blast mitigation) applications due to the continuously growing demand for high mobility with low weight. Sandwich structures can meet requirements of these applications with additional features such as high stiffness-to-weight ratio, high strength-to-weight ratio, and engineered/tailored mechanical properties for specific applications (such as functional grading of cores etc.).

Metallic foams are widely used in protective structures against impact [1-3], blast loadings [4-6] and dynamic crushing [7] due to their low density and high energy absorption capability. Competitors such as corrugated structures [8-11] were also proposed having controllable macro structures in complex shapes by providing energy absorption comparable with foam-like behavior. Metallic honeycombs are also used as core material in sandwich panels [12-17].

Compressive behavior of metallic pyramidal truss core materials was previously investigated by Lee et al. [18] at quasi-static and dynamic strain rates both experimentally and numerically. The proposed geometry showed less micro-inertial effect at increasing strain rates from quasi-static to Split Hopkinson Pressure Bar (SHPB) testing regime. At higher rates the inertia associated to the bending

\footnotetext{
* Corresponding author. Tel.: +90 232 7506780; fax: +90 2327506701.

E-mail address: alpertasdemirci@iyte.edu.tr (A. Tasdemirci).
}

and buckling of truss struts played a significant role and a major increase was seen in peak compressive stresses. A similar inertia sensitivity behavior was also reported in [19] for a thin walled combined geometry of hemisphere and cylinder, one of the configurations used as core material in the current study. It was shown that average strain rate and inertia sensitivities are more pronounced in cylindrical segment than those of hemispherical cap. For both of the constituents; inertia sensitivity is higher than strain rate sensitivity at higher impact velocities. In previous studies by Palanivelu et al. the usage of recycled beverage cans for low velocity impact applications [20] and their arrangement to obtain a sacrificial cladding [21] were investigated. They also proposed that their material can be adopted in different configurations of macro foam depending upon the loading conditions. Crushing behavior of combined geometry thin walled structures were investigated in a limited number of studies. For example, Ghamarian and Abadi [22] investigated the axial crushing of end-capped circular tubes and the effect of foam-filling on their crushing performance. They showed that the absorbed energy increased with increasing impact velocity. Gupta [23] investigated the static deformation behavior of a tubefrusta combined geometry both experimentally and numerically. Shojaeefard et al. [24] studied the quasi static crushing behavior of combined cylindrical and square section tubes. A more detailed analysis of literature on combined geometries can be found in a previous study of current authors [19].

In this study, dynamic crushing and energy absorption characteristics of a sandwich structure with combined geometry shell cores was investigated both experimentally and numerically. As core material, 
a

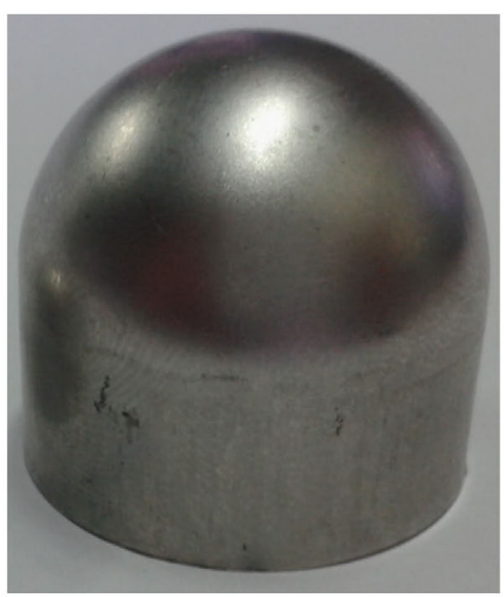

b

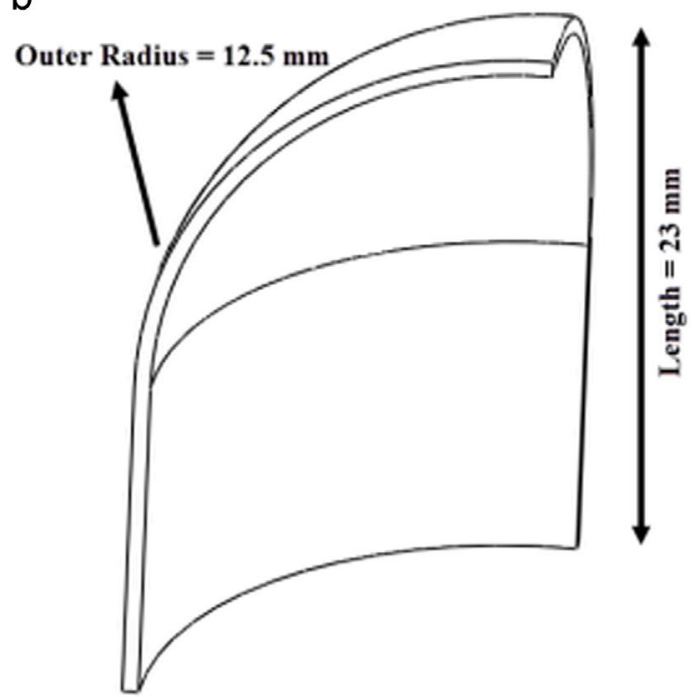

Fig. 1. (a) Combined geometry shell and (b) specimen dimensions.

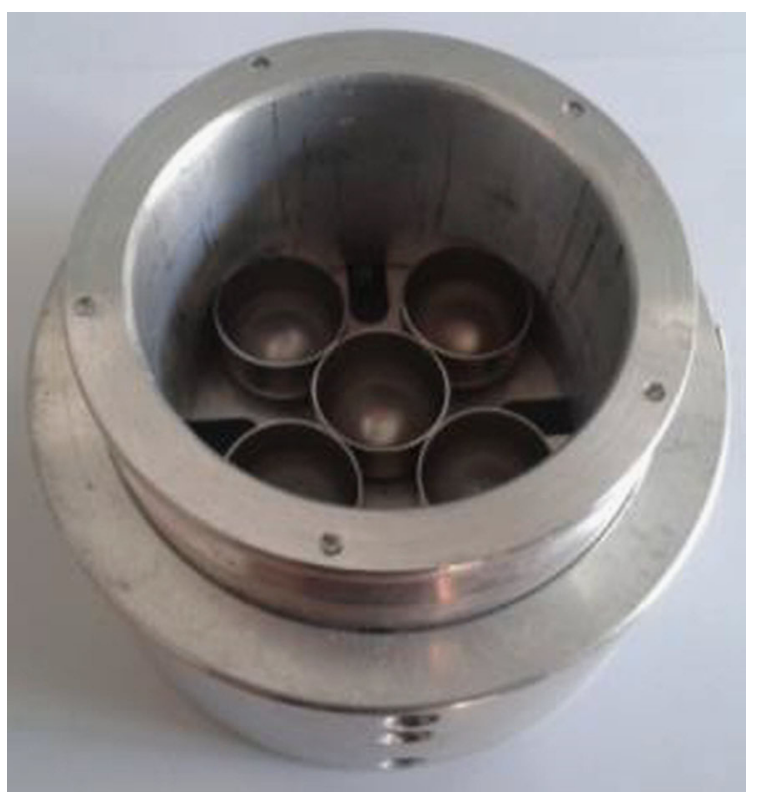

Fig. 2. Pattern used in manufacturing. a

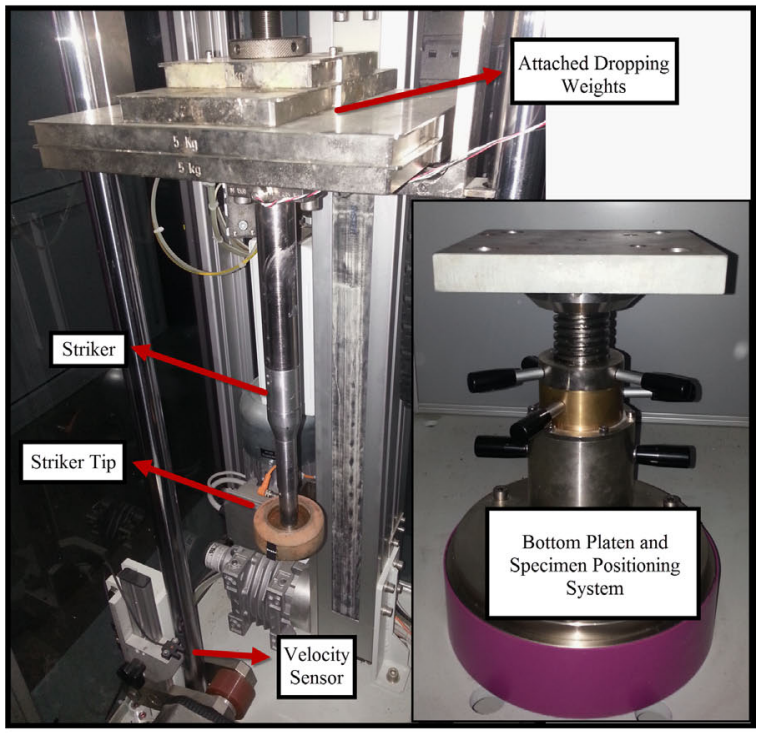

b

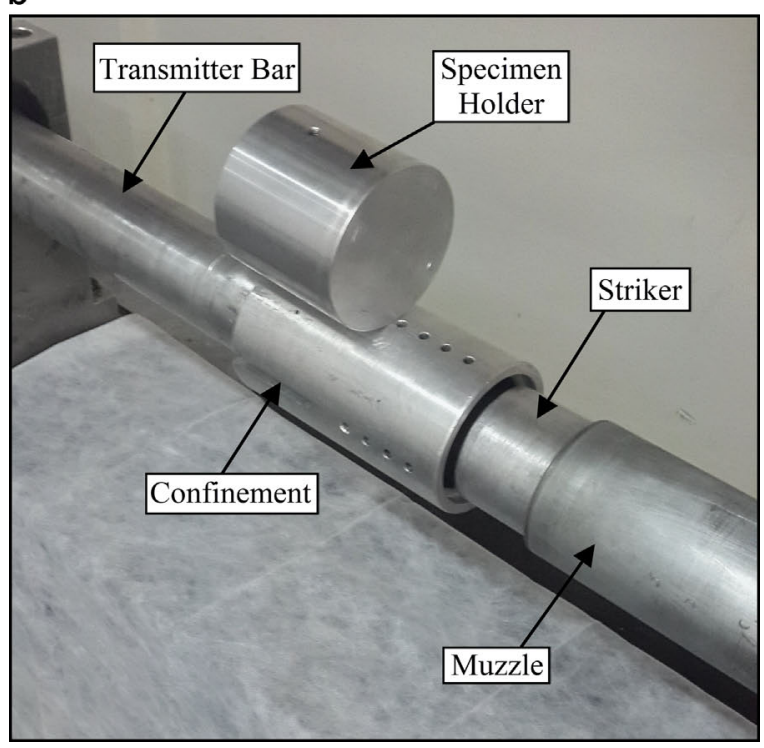

Fig. 3. (a) Fractovis plus drop weight test apparatus and (b) direct impact experimental setup.

AISI 304L combined geometry (hemisphere and cylinder) shell structure as energy absorbing structure [19] was chosen in order to provide a macro foam effect as in the study by Palanivelu et al. [21]. The static and dynamic deformation characteristics of the core material only were previously reported in a separate study. In the current study, sandwich structures containing the above mentioned core material were prepared and tested at quasi-static, intermediate and high strain rate regimes in order to see the effect of strain rate on the crushing behavior. Confined compression tests at quasi-static and high strain rates were also conducted to understand the effect of confinement. Since the structure which will eventually be used consists of repeating number of currently investigated sandwich specimen and the actual response of the whole structure will lie somewhere in between the two extremities, i.e. unconfined and confined. Numerical study was also conducted for the following purposes; (1) to better understand the deformation initiation and progression, (2) to investigate the variation of some parameters which cannot be easily experimentally determined such as stress and strain components along the 
thickness of the specimen, (3) to conduct some parametrical studies (the effect of layering or different geometrical configuration) once the models were well verified. The thorough coupled experimental and numerical study was used to understand deformation modes and to evaluate dynamic crushing and energy absorption behavior of sandwich structures.

\section{Manufacturing of sandwich structures}

The combined geometry shells used as core material in sandwich structures were manufactured by deep-drawing of $0.5 \mathrm{~mm}$ thick AISI 304L stainless steel sheet blanks. The prepared specimens contain a hemispherical cap attached to a cylindrical segment as shown in Fig. 1a. Total length of the combined geometry shell is $23 \mathrm{~mm}$ with a nominal outer diameter of $25 \mathrm{~mm}$ (Fig. 1b). Due to the nature of the deep drawing process, (the stretching of the blanks over the die surface) the drawn combined geometry shells show variations in wall thickness. The lower edge of the deep drawn cylindrical segment on the bottom side was trimmed by a cutting tool on a CNC lathe.

Combined geometry shell unit core structure is then used to fabricate a sandwich structure with a cross-shaped core configuration. In the specimens, five combined geometry shells were placed into a manufacturing pattern and $1 \mathrm{~mm}$ thick AISI 304L stainless steel face sheets were bonded using a cyanoacrylate adhesive. A point contact between hemispherical portion and face sheet and a line contact between cylindrical segment and face sheet were obtained. In order to prevent sliding of face sheets before the curing of adhesive and to have standard diameter sandwiches, a ring was placed around the manufacturing pattern (Fig. 2). Thus, sandwich specimens with $75 \mathrm{~mm}$ in diameter and $25 \mathrm{~mm}$ in length were prepared.

\section{Experimental details}

\subsection{Quasi-static experiments}

Both unconfined and confined quasi-static compression tests were conducted using a Shimadzu AG-X universal testing machine with a $300 \mathrm{kN}$ load cell. Specimens were compressed at a constant crosshead speed of $2 \mathrm{~mm} / \mathrm{min}$ corresponding to an initial nominal strain rate of $1.3 \times 10^{-3} \mathrm{~s}^{-1}$. A video extensometer was used to monitor motion of upper moving cross-head of the machine. Deformation progression scheme of unconfined quasi-static crushing experiments were recorded using a Photron FastCam high speed camera at a frame rate of $50 \mathrm{fps}$. In confined quasi-static crushing experiments a steel cylindrical ring with an outer diameter of $120 \mathrm{~mm}$ was used.

\subsection{Drop weight experiments}

Unconfined low velocity crushing experiments were carried out using a Fractovis Plus drop weight tester (Fig. 3a). The main constituents of the drop weight tester include striker, dropping weights, striker tip, and velocity sensor. The striker was attached to a $90 \mathrm{kN}$ strain-gage sensor connected to data acquisition system and readings were recorded. The striker velocity was measured by the photocells of the drop-weight tester and the tests were conducted using a $70 \mathrm{~mm}$ diameter flat end striker tip. The absorbed energy was internally calculated by integrating the force-displacement curves. Specimens were tested with an initial striker velocity of $10 \mathrm{~m} / \mathrm{s}$ (which was achieved by the additional stored energy provided by attached springs in the test system) corresponding to an initial nominal strain rate of $400 \mathrm{~s}^{-1}$. A $20 \mathrm{~kg}$ of drop weight was chosen after the calculations of required energy level from the quasi-static crushing experiments as

Table 2

Material model constants used in numerical models.

\begin{tabular}{lcll}
\hline Material & Modulus of elasticity (GPa) & Poisson's ratio & Density $\left(\mathrm{kg} / \mathrm{m}^{3}\right)$ \\
\hline 7075-T6 Al & 72 & 0.3 & 2810 \\
Steel & 193 & 0.3 & 7830 \\
\hline
\end{tabular}

a

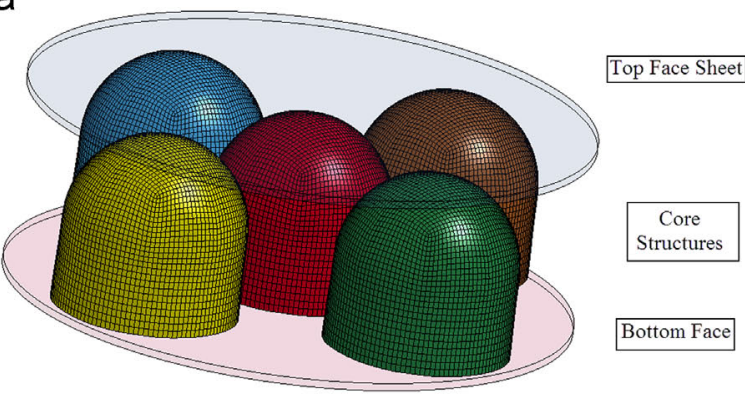

b

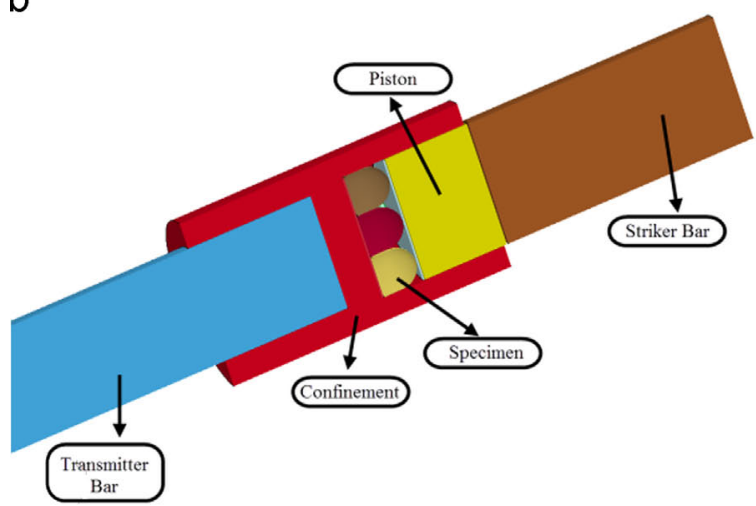

C

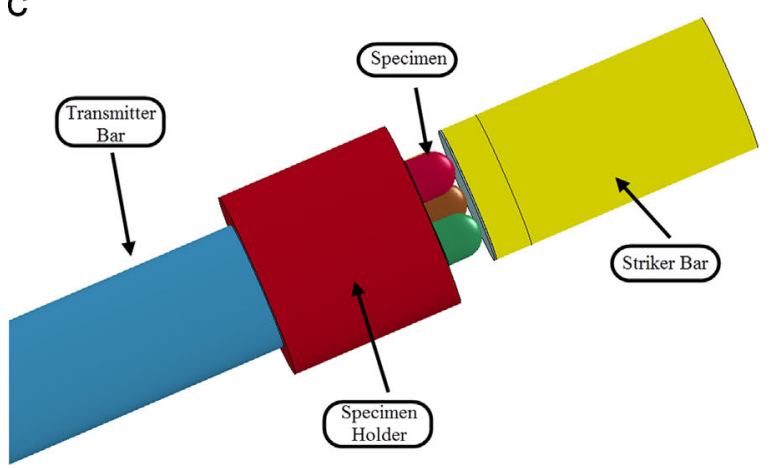

Fig. 4. (a) Numerical sandwich specimen, (b) sectional view of confined direct impact model and (c) unconfined direct impact model.

Table 1

Johnson-Cook model properties of AISI 304L stainless steel (cores and face/interlayer plates) used in numerical models.

\begin{tabular}{|c|c|c|c|c|c|c|c|c|c|}
\hline$\rho\left(\mathrm{kg} / \mathrm{m}^{3}\right)$ & $G(\mathbf{G P a})$ & $E(\mathbf{G P a})$ & $v$ & $A(\mathbf{M P a})$ & B (MPa) & $n$ & $C$ & $D 1$ & D4 \\
\hline 7830 & 80 & 193 & 0.305 & 264 & 1567.33 & 0.703 & 0.067 & 0.53467 & -0.01913 \\
\hline
\end{tabular}


a comparison. High speed camera was also used to record crushing at a frame rate of $10,000 \mathrm{fps}$.

\subsection{Direct impact experiments}

Dynamic crushing behavior of confined and unconfined sandwich structures with combined geometry shell cores at strain rates ranging between $10^{3}$ and $10^{4} \mathrm{~s}^{-1}$ was determined using a 7075-T6 aluminum direct impact experimental setup (Fig. 3b). This setup consists of a gas gun, a $150 \mathrm{~mm}$ long striker bar with a diameter of $75 \mathrm{~mm}$, and a $2000 \mathrm{~mm}$ long transmitter bar with a diameter of $70 \mathrm{~mm}$. In confined crushing tests, a confining fixture having an outer diameter of $100 \mathrm{~mm}$ was used with a clearance enough to provide radial constraint during impact event. The confinement also operated as a dimensional adaptor between $75 \mathrm{~mm}$ diameter specimen and the $70 \mathrm{~mm}$ diameter transmitter bar. In unconfined crushing tests, a specimen holder with a diameter of $100 \mathrm{~mm}$ was used only as an adaptor between specimen and transmitter bar.

In direct impact experiments, striker bar was propelled against a $50 \mathrm{~mm}$ thick piston for confined tests and directly onto specimen for unconfined tests. Initial velocity of striker bar was measured using laser velocity sensors attached to the gas gun barrel. In all tests an average initial velocity of $40 \mathrm{~m} / \mathrm{s}$ was provided corresponding to an initial nominal strain rate of $1600 \mathrm{~s}^{-1}$.

In order to calculate crushing force in dynamic experiments, transmitter bar was fitted with strain gages and strain history $\left(\varepsilon_{T}\right)$ was recorded using an oscilloscope. Then strain history was used to calculate bar stress $\left(\sigma_{T}\right)$ and was converted to transmitted force history $\left(F_{\text {Dynamic }}\right)$ which is the dynamic crushing force of sandwich structure. Equations used in the procedure are as follows;

$\sigma_{T}=E_{\text {bar }} \varepsilon_{T}$

$F_{\text {Dynamic }}=\sigma_{T} A_{b a r}$

High speed camera was also used to record crushing scheme in dynamic unconfined experiments with a frame rate of 18,000 fps. In confined experiments deformation scheme was revealed by numerical simulations.

Finally, all quasi-static, drop-weight and direct impact tests were repeated for three times and only representative test results were shown in the present study.

\section{Finite element modeling}

In this study, numerical simulations were conducted in order to generate data that cannot be readily obtained from experimental study such as; inertial and strain rate effects for various initial conditions and multi-layering effects. LS-DYNA 971 explicit commercial finite element solver was used throughout the study.

For the first part of the finite element modeling, combined geometry shell structures were numerically prepared by modeling deep-drawing process and initial strain and stress history of deformed material were taken into account using Restart Analysis Technique. The details of numerical specimen preparation can be found in [19]. In the simulations, Johnson-Cook (J-C) material model was used. In this material model, the equivalent stress $\left(\sigma_{e q}\right)$ is expressed as

$\sigma_{e q}=\left(A+B \varepsilon_{e q}^{n}\right)\left(1+C \ln \left(\dot{\varepsilon}_{e q}^{*}\right)\right)\left(1-T^{* m}\right)$

where, $\varepsilon_{e q}$ is the equivalent plastic strain and $A, B, n, C$ and $m$ are the material constants. The dimensionless equivalent plastic strain rate $\left(\dot{\varepsilon}_{e q}^{*}\right)$ is given by $\dot{\varepsilon}_{e q}^{*}=\dot{\varepsilon}_{e q} / \dot{\varepsilon}_{0}$, where $\dot{\varepsilon}_{0}$ is a user defined reference strain rate, and $\left(\dot{\varepsilon}_{e q}\right)$ is the equivalent plastic strain rate. The homologous temperature $\left(T^{*}\right)$ is defined as $T^{*}=\left(T-T_{r}\right) /\left(T_{m}-T_{r}\right)$, where $T$ is the absolute temperature, $T_{r}$ is the room temperature and
$T_{m}$ is the melting temperature. The failure model considered in this study is based on Johnson-Cook damage model. According to Johnson-Cook damage model, strain at fracture can be written as
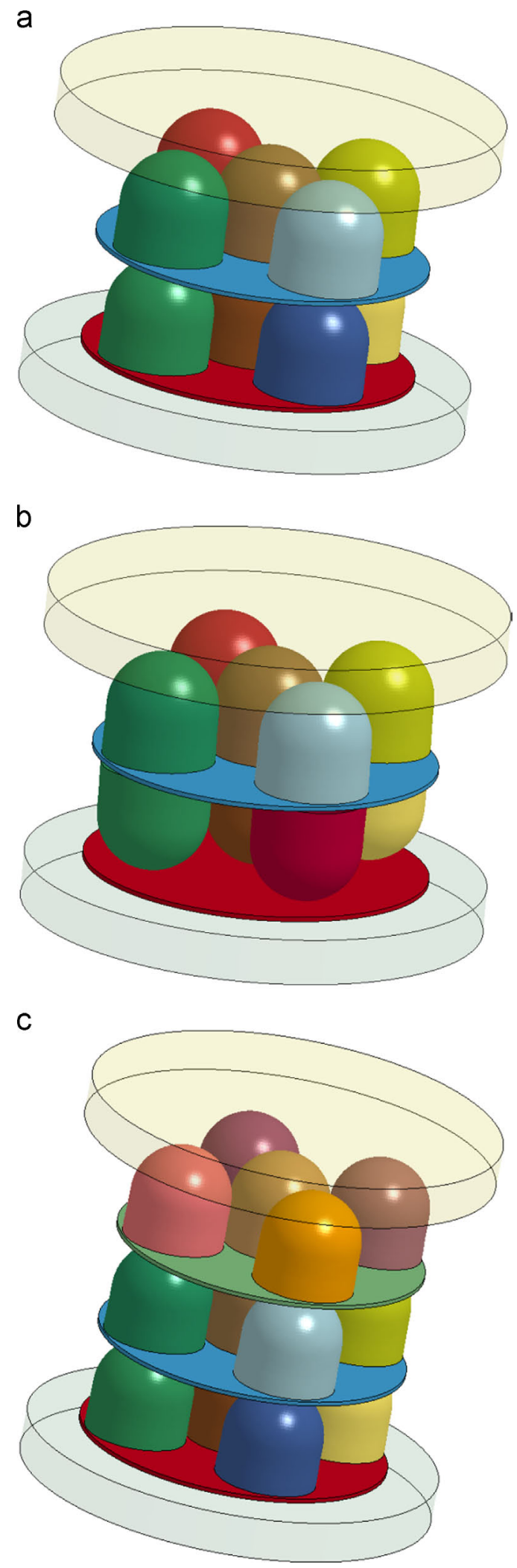

Fig. 5. (a) Sequential, (b) opposite two layered specimens, and (c) three layered specimen. 
follows:

$\varepsilon_{f}=\left[D_{1}+D_{2} e^{D_{3} \sigma^{*}}\right]\left[1+D_{4} \ln \left(\frac{\dot{\varepsilon}}{\dot{\varepsilon}_{0}}\right)\right]\left(1+D_{5} T^{*}\right)$

where $D_{1}, D_{2}, D_{3}, D_{4}$ and $D_{5}$ are damage parameters, $\sigma^{*}=\sigma_{m} / \sigma_{e}$ is stress triaxiality ratio, where $\sigma_{m}$ and $\sigma_{e}$ are the mean and effective stresses, respectively. In the current study, the stress state does not vary significantly during compression. Thus, the following simplified form concentrating only on the strain rate dependency was considered.

$\varepsilon_{f}=D_{1}\left[1+D_{4} \ln \left(\frac{\dot{\varepsilon}}{\dot{\varepsilon}_{0}}\right)\right]$

Note also that, thermal effects on both strength and damage models were neglected. The determined $\mathrm{J}-\mathrm{C}$ material model constants of AISI 304L stainless steel (cores and face/interlayer plates) are tabulated in Table 1.

The finite element model of sandwich specimen can be seen in Fig. 4a. The quasi-static and drop-weight test numerical models consisted of a moving rigid upper plate, specimen and stationary rigid lower plate. In the confined quasi-static crushing simulations, a rigid confinement ring was also modeled with the appropriate clearance as in the experiments. The displacement rates in quasistatic deformation problems were relatively low for an explicit solver; therefore, mass scaling was applied in order to obtain reasonably small solution times. In mass scaling, the density of specimen was scaled down by a factor of 1000 and the upper cross-head velocity was set at $10 \mathrm{~m} \mathrm{~s}^{-1}$. The ratio of kinetic energy (KE) to total internal energy was found to be less than $4 \%$ over the period of crushing process, ensuring the quasi-static strain rates. The lower plate was fully constrained in all directions.

In the drop weight simulations, the top rigid plate moved along its thickness axis with a downward velocity and node based mass lumping methodology was followed in order to match the total weight of the drop-weight tester cross-head. For both quasi-static and drop-weight test simulations, two different types of contact were used. For the combined geometry shell cores and face sheets, an automatic single surface contact was used to account for the contact between folds during the deformation, and contact between core materials and face sheets. While an automatic surface to surface contact was applied between the face sheets and rigid top/bottom plates. The strength of the adhesive used was relatively low and broken down as soon as the compressive load was applied; it was not taken into account in the numerical model.

Finite element models used in the direct impact test simulations can be seen in Fig. $4 \mathrm{~b}$ and $\mathrm{c}$. In the simulations surface to surface contact algorithms were used in order to define contact between the parts of experimental set-up. Contacts between the specimens themselves and parts of experimental set-up were modeled with automatic surface to surface contact algorithm. An initial velocity was assigned to the striker bar. In order to compare numerical and experimental results, elements coinciding with the position of strain gages in experiments were determined, stress history was recorded and crushing forces were calculated using Eq. (2). Material model constants of parts are given in Table 2.

In the numerical simulations, core materials were modeled using Belytschko-Tsay shell elements with five integration points through
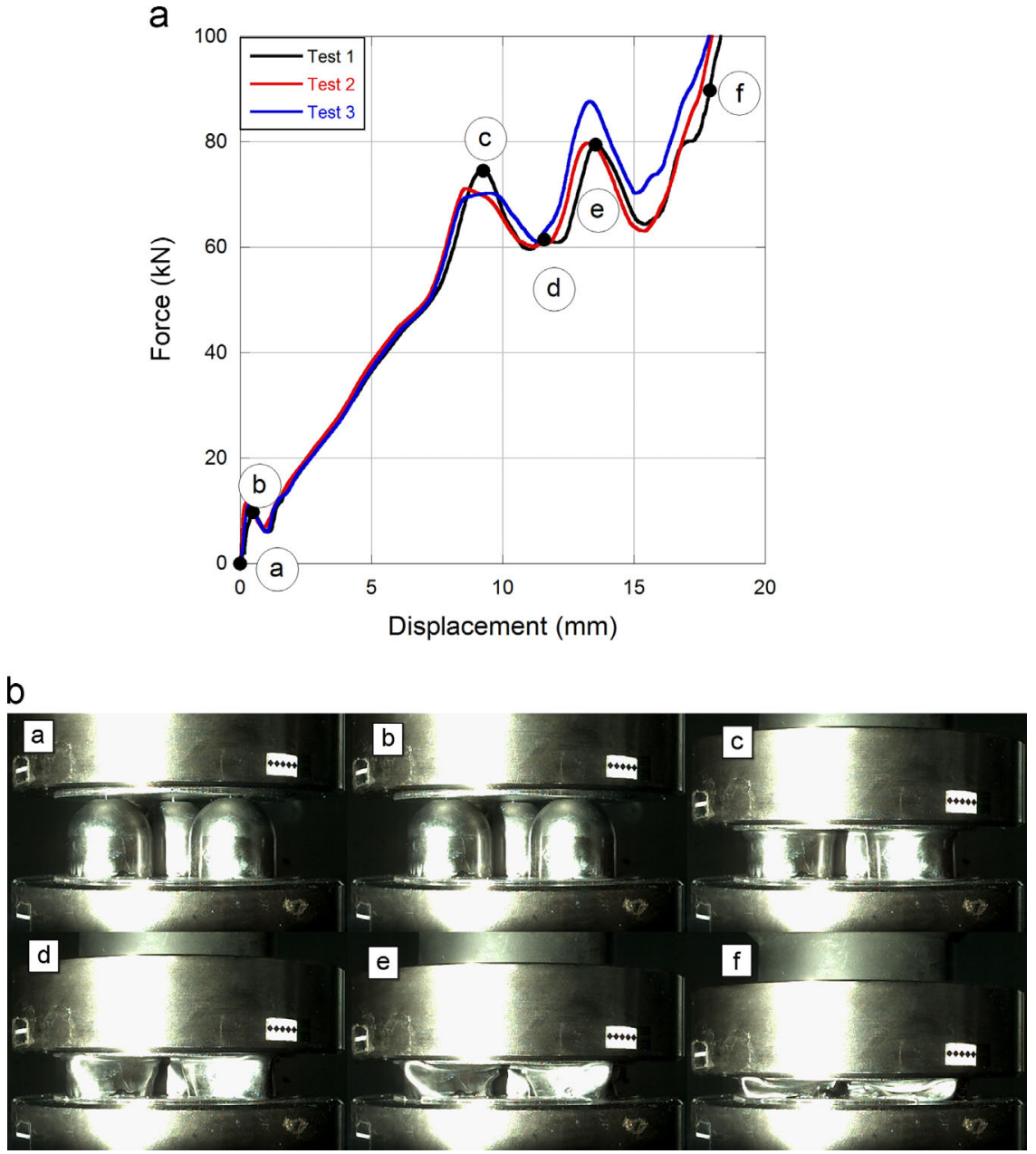

Fig. 6. (a) The force-displacement curves of three unconfined quasi-static crushing tests and (b) deformation pictures of one representative test. 
the thickness. Cross-heads, striker and transmitter bars, and specimen holders were modeled using eight-node constant stress solid elements. A static friction coefficient of 0.3 and a dynamic friction coefficient of 0.2 between all surfaces contacting were assumed in the study. In the numerical model, the air pressure presumably arisen from compression of the enclosed air is assumed to have insignificant effect on the force values as with metallic closed cell foams. Hence, the air was not modeled explicitly.

Once numerical model was well verified then the numerical study was extended in order to reveal the effect of inertia and base material's strain rate sensitivity on the deformation and energy absorption behavior of sandwich structures at different loading rates. Additional numerical simulations were prepared with different constant impact velocities and models were re-run where the base material was assumed to be rate insensitive.

Constant deformation velocity simulations at $50 \mathrm{~m} / \mathrm{s}$ were used in order to investigate the effect of multilayering on crushing response. Two different configurations of two-layered specimens; i.e. sequential and opposite specimens were prepared and can be seen in Fig. $5 a$ and b. In potential engineering applications of the currently studied sandwich structures as blast protection, many repeating unit cells will be stacked along the thickness and inplane directions. Thus, the investigation of the effect of axial rotation and/or angular misalignment of these repeating cells will become important. In this study this effect was also numerically investigated. A sequential three layer specimen was also prepared to see the effect of layering and numerically deformed under similar conditions (Fig. 5c).

\section{Results and discussions}

\subsection{Experimental and numerical}

The force-displacement curves of three different unconfined quasistatic crushing tests and the deformation pictures of one representative test are shown in Fig. $6 a$ and b, respectively. The letters given in the inset of Fig. $6 \mathrm{a}$ and $\mathrm{b}$ correspond to the deformation sequences. A progressive collapse characteristic which can also be verified by the help of damage sequence recordings is observed. As expected from a progressively collapsing structure, a $75 \mathrm{kN}$ peak marked with (c), due to buckling of hemispherical portion, was followed by a second peak of $80 \mathrm{kN}$ (marked with (e)) indicating the buckling of cylindrical portion. Each peak corresponding to the buckling of core structure constituents is followed by load drop due to buckling load overcome where the lateral motion of plastic hinges with lower loads occurred. It is observed that the combined geometry shell placed in the center of the specimen is radially constrained by the circumferentially placed neighboring shells and therefore its lateral motion is partly prevented by them (Fig. 7b). As deformation progressed and the planform area (contact area between the core units and faces) increased (friction increased between core units and face sheets) densification occurred following the second peak corresponding to the buckling of cylindrical portion.

Comparison of unconfined and confined quasi-static compression tests is given in Fig. 7 along with the top views of specimens after the tests. A similar progressive collapse behavior is also seen for confined quasi-static crushing test. However, higher buckling loads at lower deformation levels are observed for both constituents of core structures. The effect of confinement is shown with the dashed area between the force-displacement curves. In the confined test, after some deformation level, rolling plastic hinge of hemispherical portion of circumferentially placed core structures started to contact with the confinement wall and their lateral motion was prevented. Therefore, higher buckling load had to be

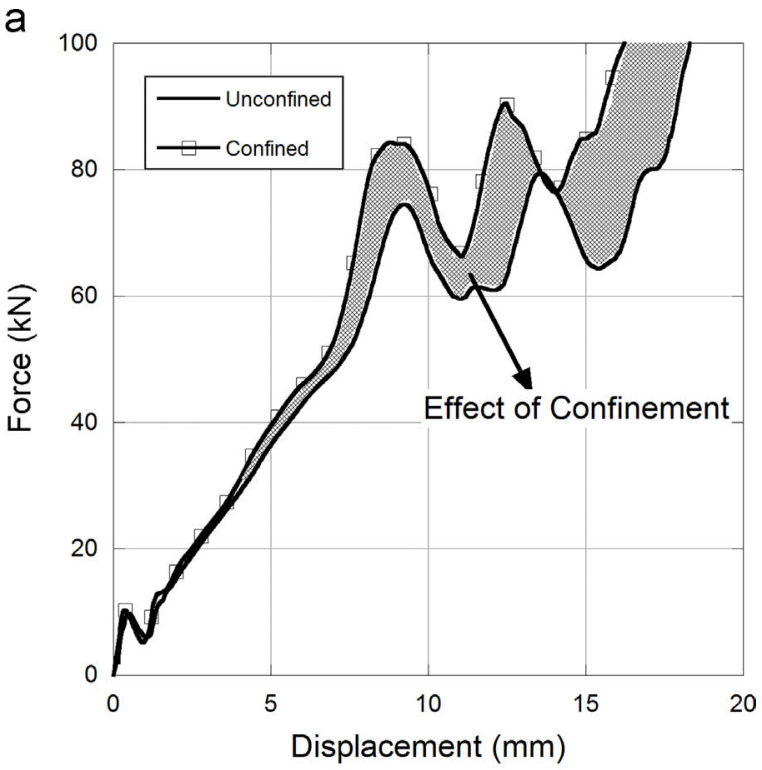

b

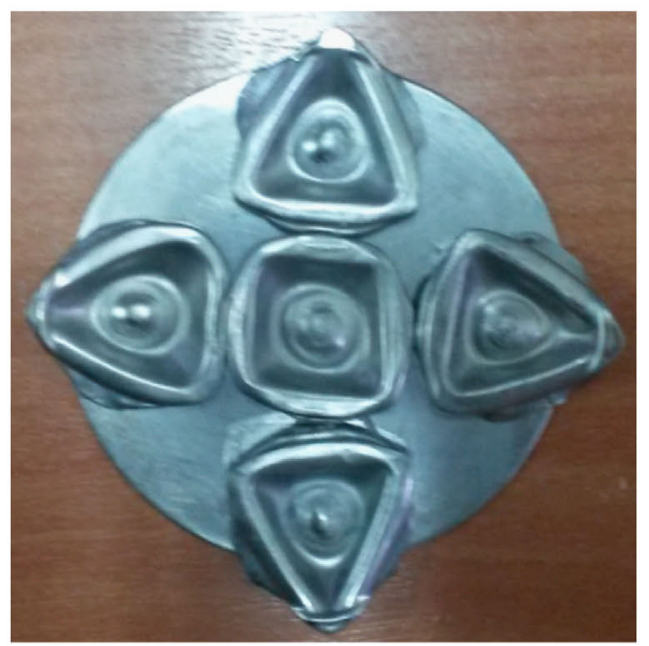

C

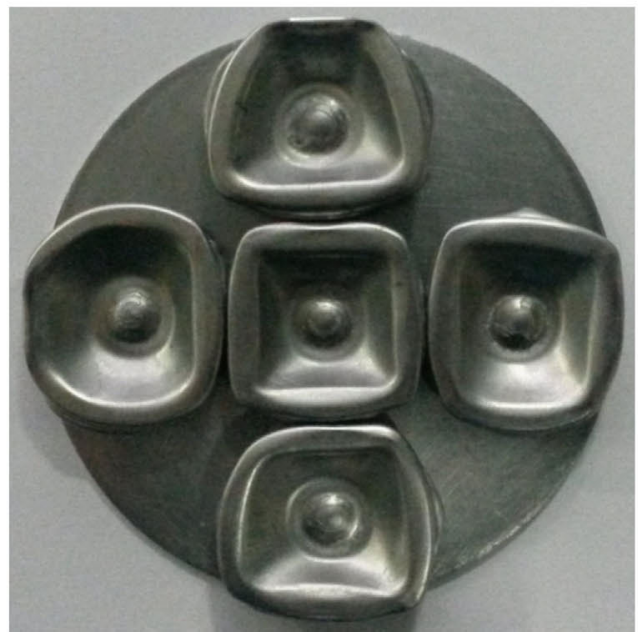

Fig. 7. (a) Comparison of unconfined and confined quasi-static crushing test results, deformed top views of (b) unconfined, and (c) confined specimen.

applied to overcome the support provided by the confinement wall. Same is valid for the cylindrical portion. Kılıçaslan et al. [8] were reported similar results for a confined corrugated core sandwich structure; which was also a progressively collapsing 
structure. In their study, as a result of confining, buckling and post buckling stresses increased.

Effect of confinement can be seen in the deformed views of specimens given in Fig. $7 \mathrm{~b}$ and c. With the lack of radial constraint in an unconfined test, outer core units tends to deform in a triangular asymmetric form and crushed in a more symmetric fashion in confined test with the additional flattening of sides of outer core units as a result of friction between core units and the confinement wall.

In drop-weight test of sandwich specimen, an initial maximum load of $75 \mathrm{kN}$ at $10.4 \mathrm{~mm}$ of deformation and a second peak load of $80 \mathrm{kN}$ due to buckling of cylindrical portion are observed, Fig. 8 . Progressive crushing behavior can still be seen in both force- displacement curve and deformation scheme. Except for the shift in the deformation values, result is almost the same with that of quasi-static. This is mainly due to the low levels of strain rate sensitivity and inertial effects at relatively lower velocities attained during drop-weight tests, which is fully in accordance with the behavior observed when the combined geometry shells deformed only [19]. Deformation of the structure started with typical inward dimpling, which is asymmetric due to the interaction between the adjacent core units. This mode ended with the formation of plastic hinges and due to the lack of radial constraint core units were squeezed out.

Having seen that at relatively lower velocities, strain rate sensitivity and inertial effects both have insignificant effect on the deformation
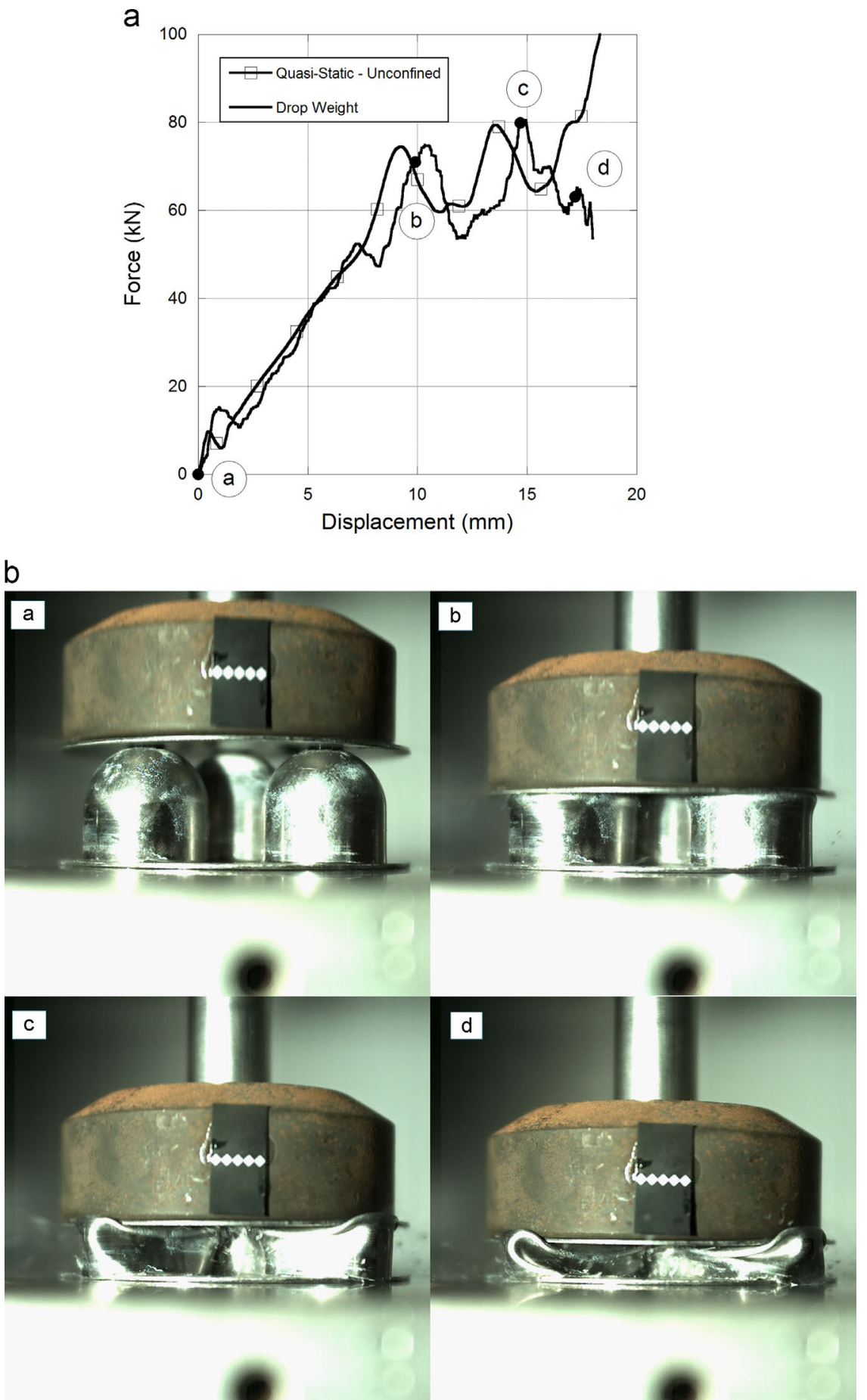

Fig. 8. (a) Drop-weight crushing result comparatively with unconfined quasi-static crushing test result and (b) deformation scheme. 
characteristics; study continued with the direct impact experim ents to achieve higher deformation rates. In Fig. 9a force histories of unconfined and confined direct impact experiments are given comparatively. Deformation sequence can also be seen for unconfined test in Fig. 9b. As can be seen from Fig. 9a, for both unconfined and confined direct impact test results showed similar behavior except for the force values recorded during confined tests were higher than those of unconfined due to the interaction effects. For both of the tests average forces were higher than those of quasi-static and low velocity tests. Kilıçaslan et al. [25] also reported an increase in peak crushing stress for a corrugated core sandwich structure and related this phenomenon to inertial effect arising from high impact velocity. Although this is also valid for the case studied in here, change of deformation mode with increasing impact velocity can obviously be deduced by comparing Fig. 9b with Fig. 6b. In the unconfined direct impact experiment, circumferentially placed core units tends to move in the radial direction during the course of deformation. In the confined direct impact test, this radial movement is prevented and that resulted in an increase in the crushing load, as can be seen in Fig. 9a. Some of this increase might also be resulted from the friction between the core units and the inner walls of confining ring.

Experimental and numerical force-displacement curves obtained from quasi-static, low velocity and dynamic crushing tests are given in Fig. 10a-e respectively. In unconfined quasi-static simulation, peaks corresponding to the buckling of constituents are slightly overestimated. Similar findings are also observed for confined quasistatic and drop weight crushing behavior. These slight variations might arise due to the imperfections resulting from tilting of unit cores while bonding. Similar imperfection effects were previously reported for an instability collapsing structure [18], for a honeycomb material [26] and for a cylindrical tube [27]. Furthermore, the alignment of the sample and cross-head/striker in the model was assumed to be perfectly axial, while in the experiments the misalignment of the sample and cross-head/striker tended to the deviation in the higher displacement values. Final displacement values might vary since both the drop-weight and direct impact
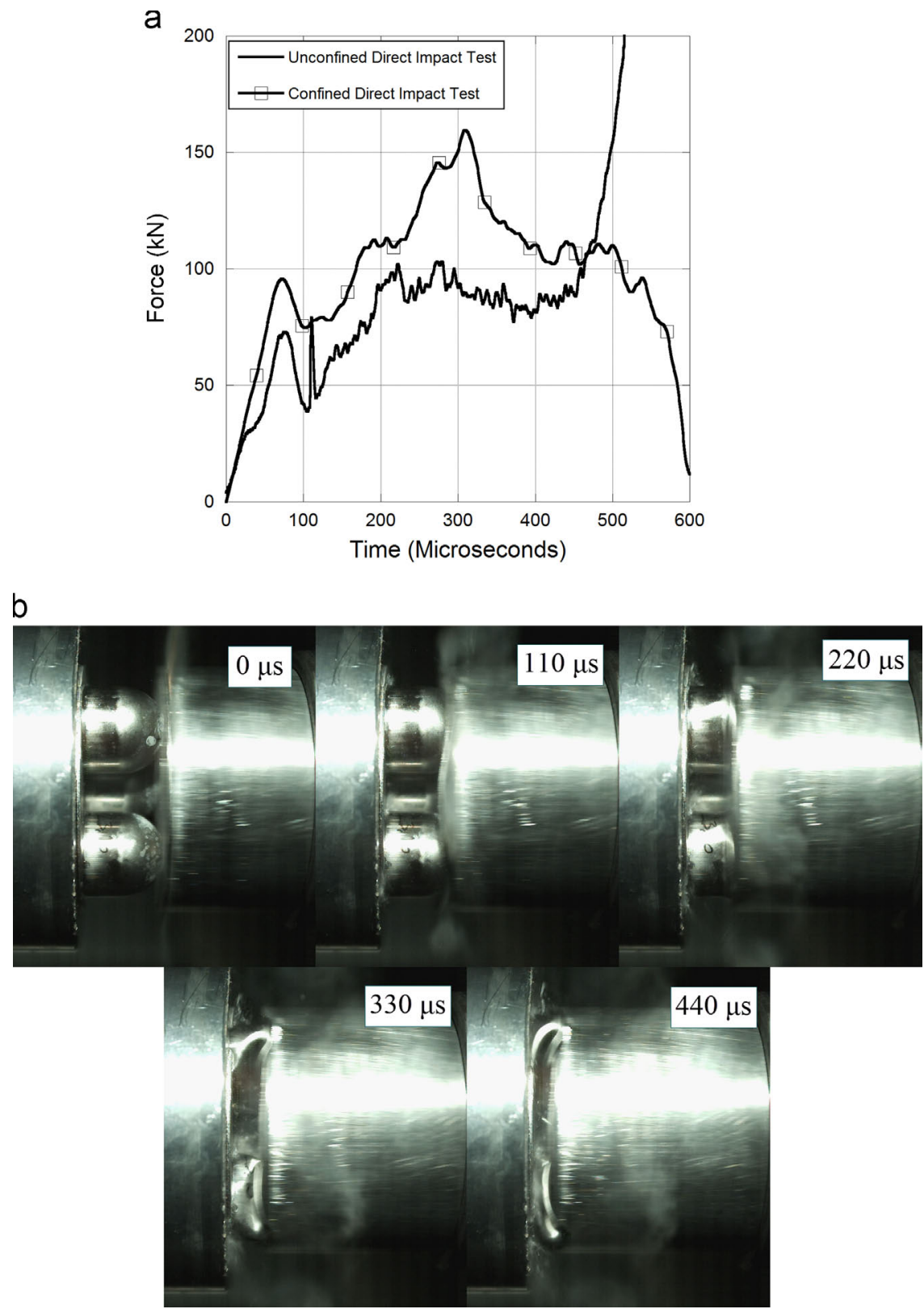

Fig. 9. (a) Unconfined and confined direct impact crushing test results and (b) deformation scheme of unconfined experiment. 
a

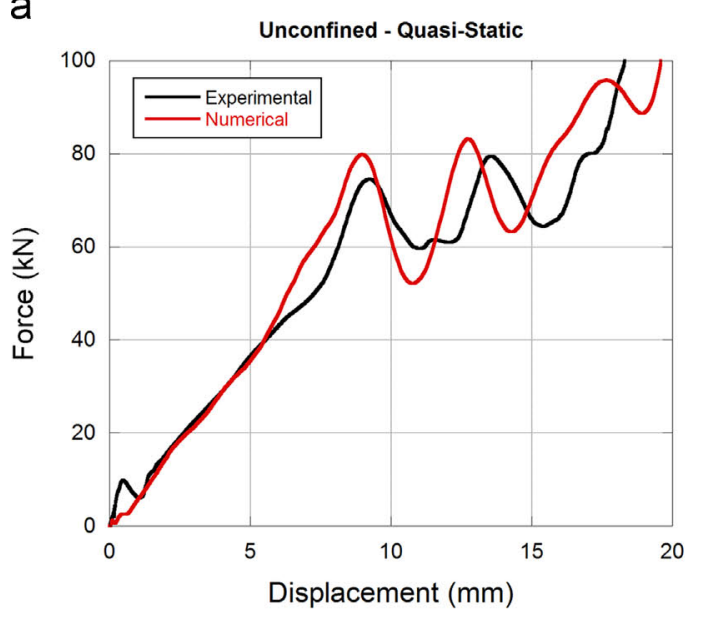

C

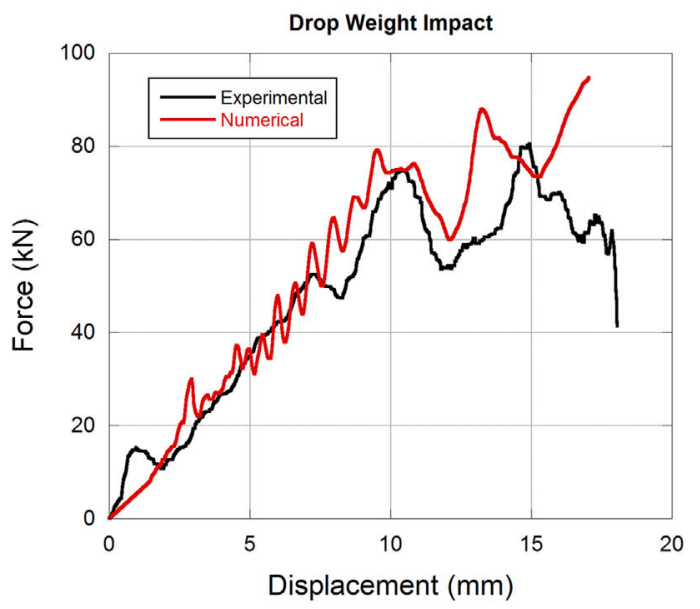

b

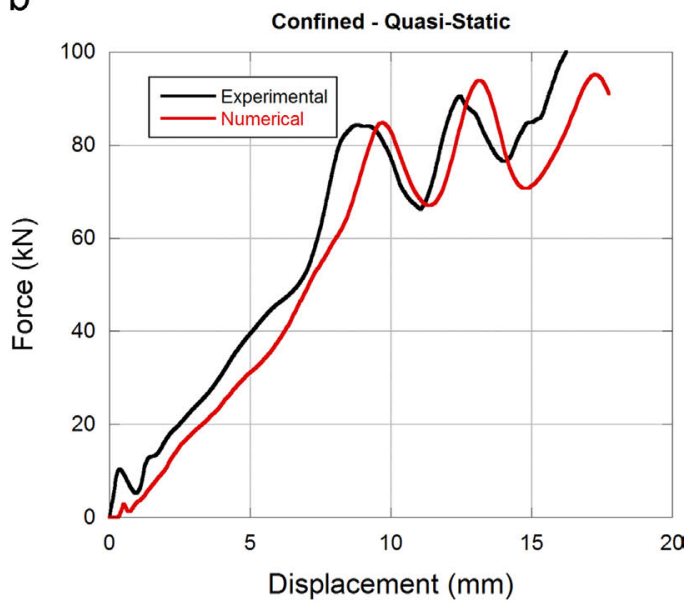

d

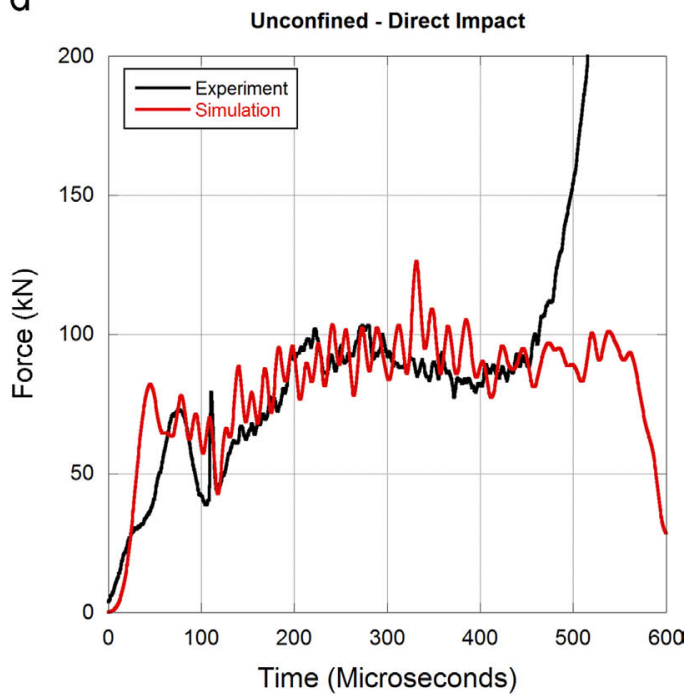

e

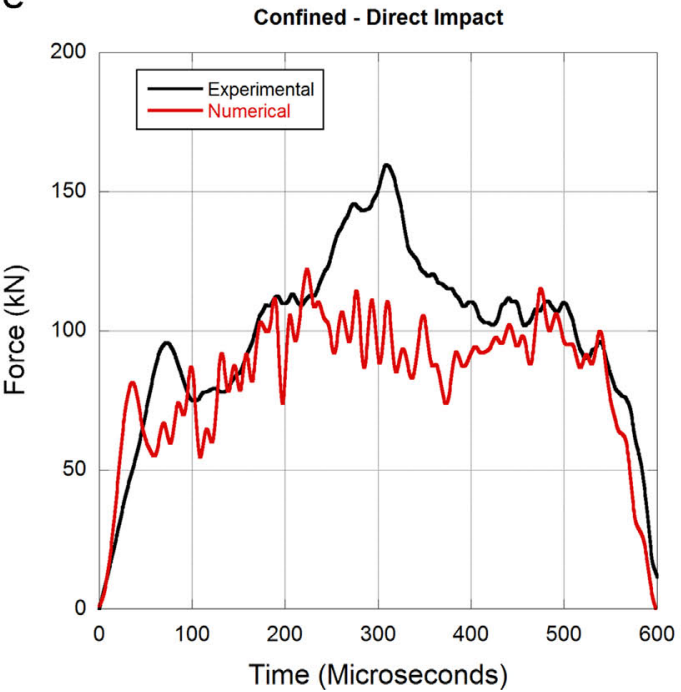

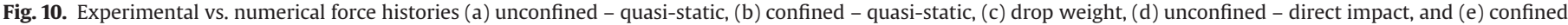
- direct impact.

tests were load controlled. During the initial stages of the deformation, mainly the hemispherical caps of the core units deformed. Then cylindrical segment started to buckle and folds were formed. At the later stages of the deformation, for the case of unconfined configuration, surrounding core units started to move in the inplane direction. This movement was not fully symmetric due to the aforementioned alignment issues. Thus, the numerical errors started to increase at the later stages of deformation. 
a
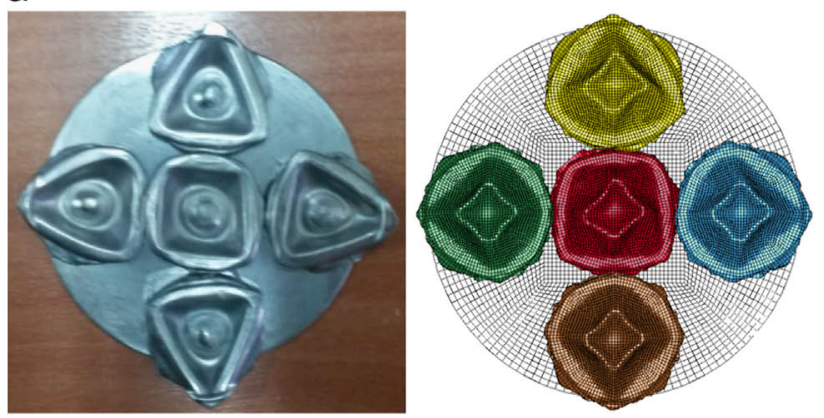

C

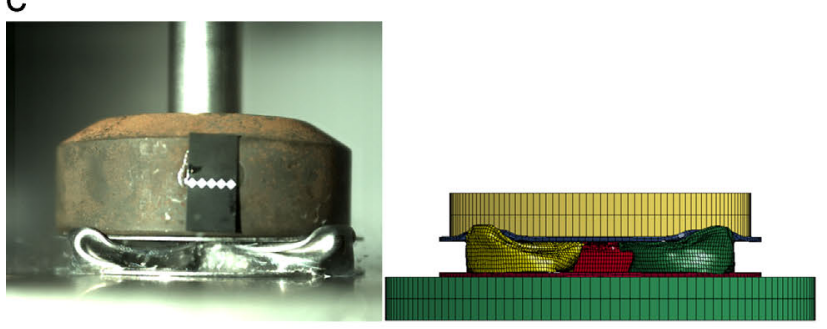

b
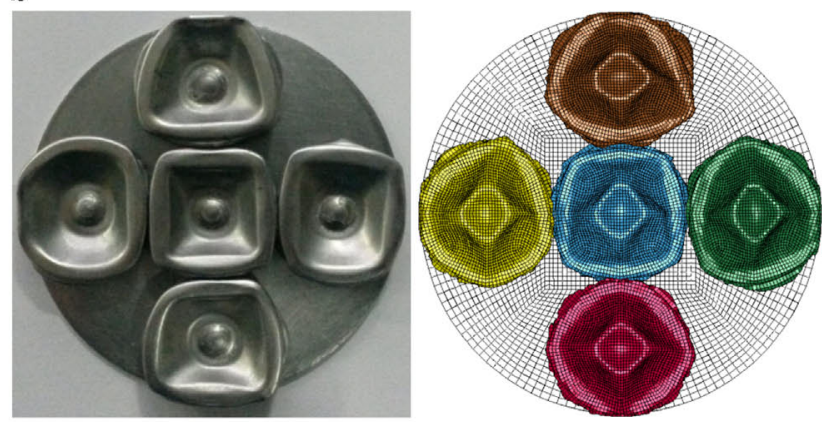

d
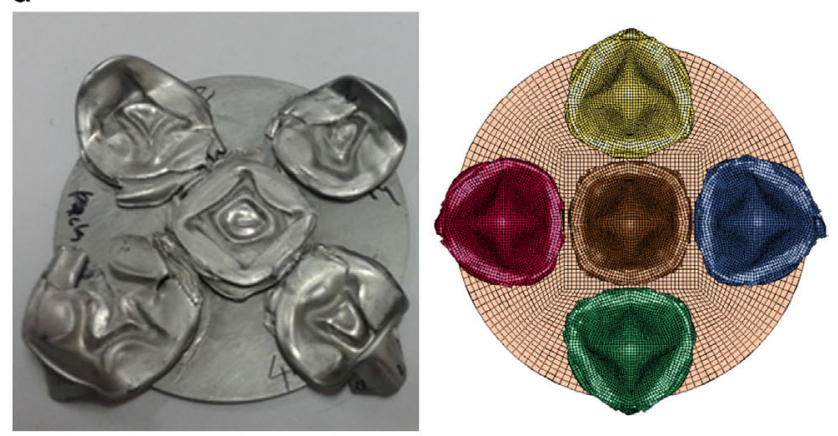
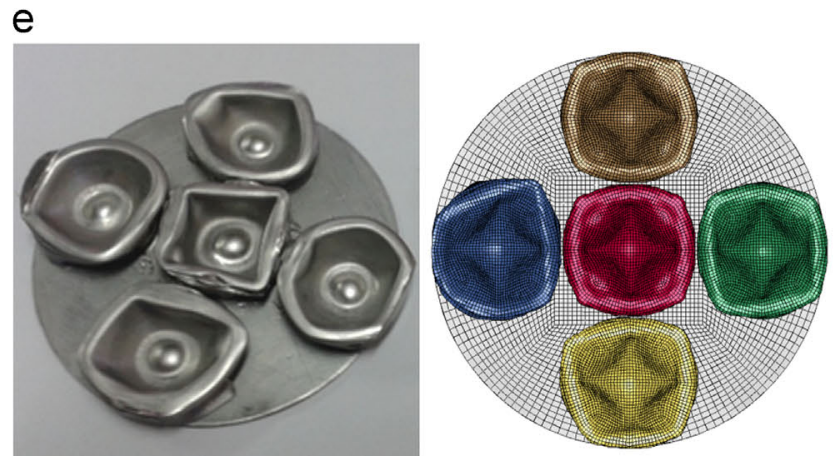

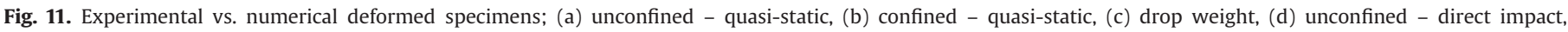
and (e) confined - direct impact.

The validity of numerical simulations is also confirmed with the comparison of deformed shapes of sandwich specimens from experiments and simulations (Fig. 11). In both experimental and numerical simulations of confined tests due to the local flattening of core walls a trapezoidal cross-sectional form of deformation is observed, while in unconfined tests the cross-sectional form of deformation switches to a triangular shape. As shown in Fig. 11e, the mode of deformation does not change significantly as the deformation rate increases.

\subsection{Rate sensitivity and inertia}

There are two types of energy absorbing structures classified in terms of distinct shapes of load-displacement curves [28-30]. A flat-topped load displacement curve is a sign of a Type I structure, while a dramatically decreasing curve is a characteristic of a Type II structure. It is well known so far that Type II structures are more sensitive in terms of both inertia and strain rate than Type I structures [28]. The energy absorption efficiency of Type II structures was shown to be enhanced by the structure's material strain rate sensitivity [30].
In a previous study of current authors [19] it was shown that combined geometry structure is a combination of a Type I hemispherical portion and a Type II cylindrical portion. Therefore; the effects of inertia and strain rate on the deformation is shown to be the blend of the behavior of the constituents. In addition, an interaction between the unit core materials in a sandwich structure is obviously apparent. Therefore, in order to understand the effects of strain rate and inertia while incorporating the interaction between core materials in a sandwich structure was investigated in the current study. For this purpose, numerical simulations were prepared for both unconfined and confined conditions due to the fact that in engineering applications of this type of structures lay between those two configurations. In order to distinguish the effects of strain rate and inertia, simulations were prepared by assigning constant crossheads velocities from 50 to $200 \mathrm{~m} / \mathrm{s}$ with both strain rate insensitive and sensitive material models.

In Fig. 12a, numerical results from strain rate insensitive and sensitive models at $200 \mathrm{~m} / \mathrm{s}$ constant crosshead velocity can be seen comparatively with the quasi-static simulation results in terms of mean crush load vs. displacement. As can be seen, dashed area between strain rate insensitive model and quasi-static model represents the increase due to effect of micro inertia at the specified velocity. Additional effect of strain rate can be computed from the 
a
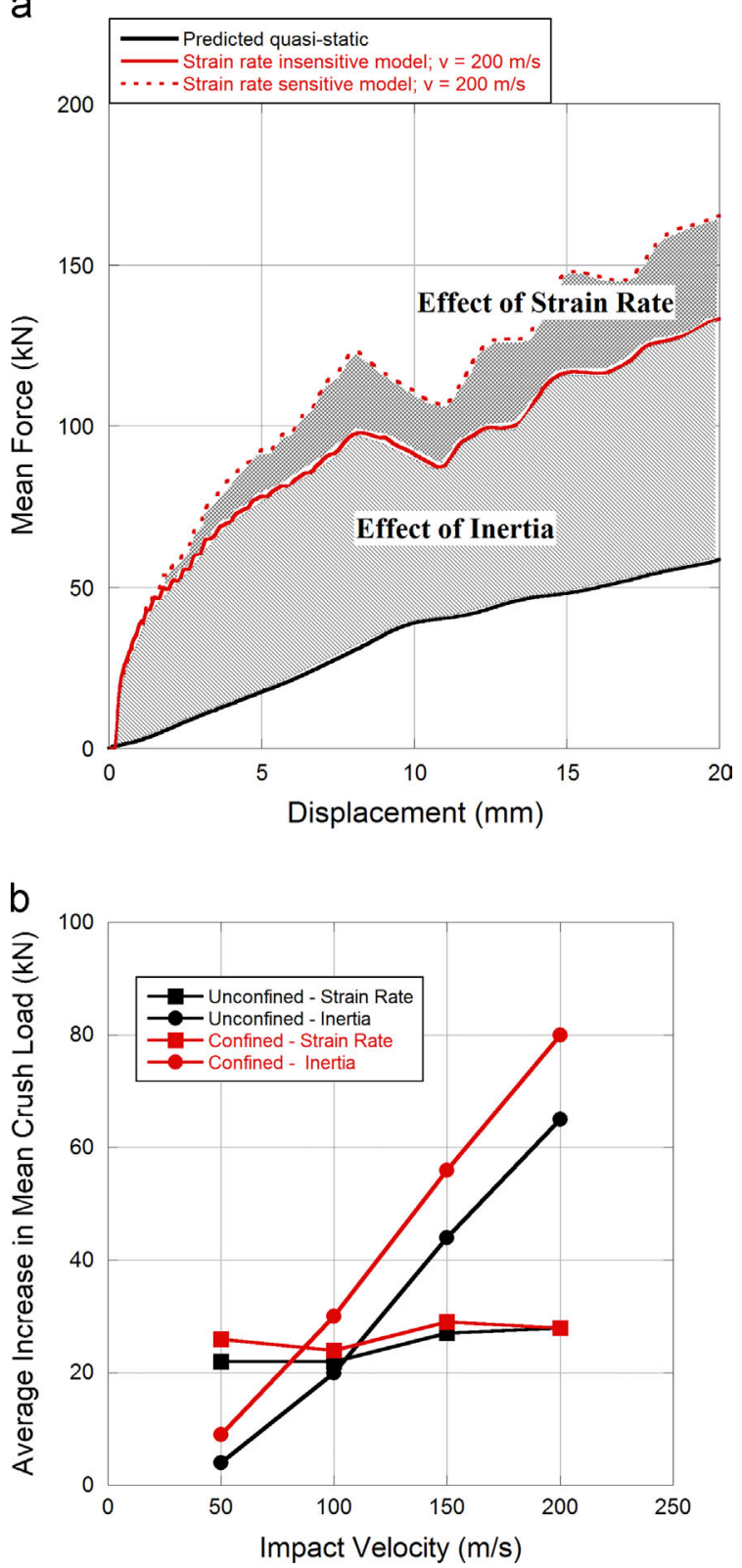

Fig. 12. (a) Effect of strain rate and inertia for $200 \mathrm{~m} / \mathrm{s}$ simulation, (b) average increase in mean crush load vs. impact velocity.

difference between strain rate sensitive and insensitive models as seen in Fig. 12a. By conducting numerical simulations at various impact velocities, average increase in mean crush loads are calculated and plotted against impact velocity (Fig. 12b). For both unconfined and confined configurations, the effect of inertia is more noticeable when compared with that of strain rate particularly at higher impact velocities. Even, the increase due to strain rate is nearly independent of impact velocity, which is in consistence with the previous study on the behavior of unit core material [19]. Increase due to strain rate and inertial effect is found to be higher for confined case than that of unconfined condition. As can be seen, curves of both unconfined and confined inertial effects are nearly parallel revealing that their effects are comparable but with some amount of offset due to the effect of confinement at all velocities. This offset might arise due to the effect of radial constraint induced by the confinement and also the friction between the unit cores and the confinement lateral wall. At higher velocities, the effect of strain rate becomes almost independent of confinement condition.

\subsection{Multilayering}

Multilayering of lightweight core sandwich structures has significant application potentials where higher amount of energy absorption needed. In this type of applications an effective way in terms of increasing absorbed energy with a reasonably low increase in total weight of the structure is to place some numbers of repetitive unit core layers and it is not unlikely to observe misalignment of unit cores in the neighboring layers. Thus, it is worth for investigating the effect of misalignment/rotation on the energy absorption characteristics of the structure. Multilayering usually results in high energy absorption with the increase of allowable compression values. Besides, the interaction between the adjacent layers might cause change in deformation modes and therefore increase in crushing load and absorbed energy. Multilayered configurations were investigated numerically with a constant $50 \mathrm{~m} / \mathrm{s}$ impact velocity. Three alternative configurations (Fig. 5) were compared with a single layer case.

In Fig. 13 mean load vs. \% displacement curves can be seen for single and multilayered sandwich structures. \% displacement was calculated by dividing instantaneous displacement to the total thickness of individual sandwiches. As can be seen from the figure, similar results are observed for all types of multilayered specimens up to $\sim 10 \%$ displacement. The lowest mean crushing force was calculated for single layer sandwich and the highest for sequential two layer sandwich. Interaction between adjacent layers shows its effect after 10\% displacement. For the configurations investigated, the plates separating the core layers were slightly bent during the course of deformation and it was found that the ratio of energy absorbed by interlayer plate to the total energy absorbed was remained as $3 \%$ and lower.

In the current study, a possible defect or an engineered feature called axial rotation/misalignment of adjacent layers relative to each other in two layered configuration is also investigated, Fig. 14a. For lower misalignment angles, this might represent a possible manufacturing defect or for higher misalignment angles this could be a desired feature if energy absorption could be increased by the deformation mode change.

In Fig. 14b, SAE vs. misalignment angle are given. As can be seen in figure, all multilayered configurations absorb higher amount of energy than single layer with a reasonable increase in the weight of the sandwich. For both two layered configurations, SAE values are higher than single layer configuration. Sequential configurations have higher SAE values than opposite configurations. This is the result of

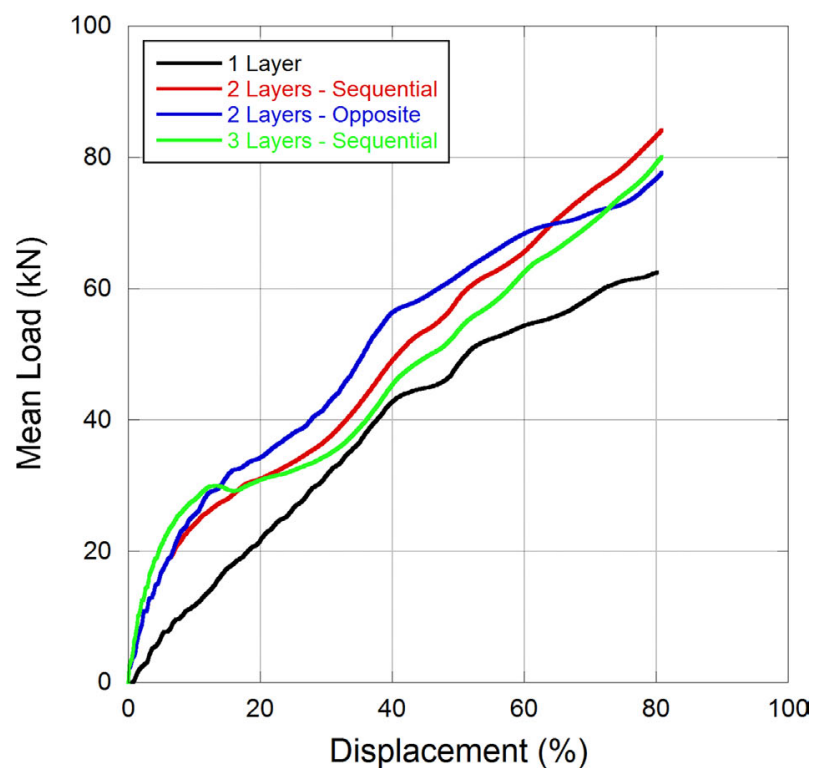

Fig. 13. Mean load vs. \% displacement curves of single and multilayered sandwiches. 
a

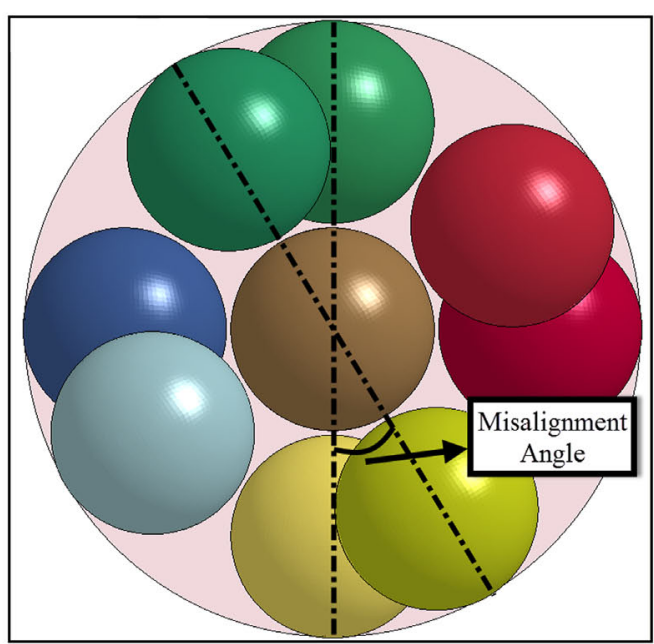

b

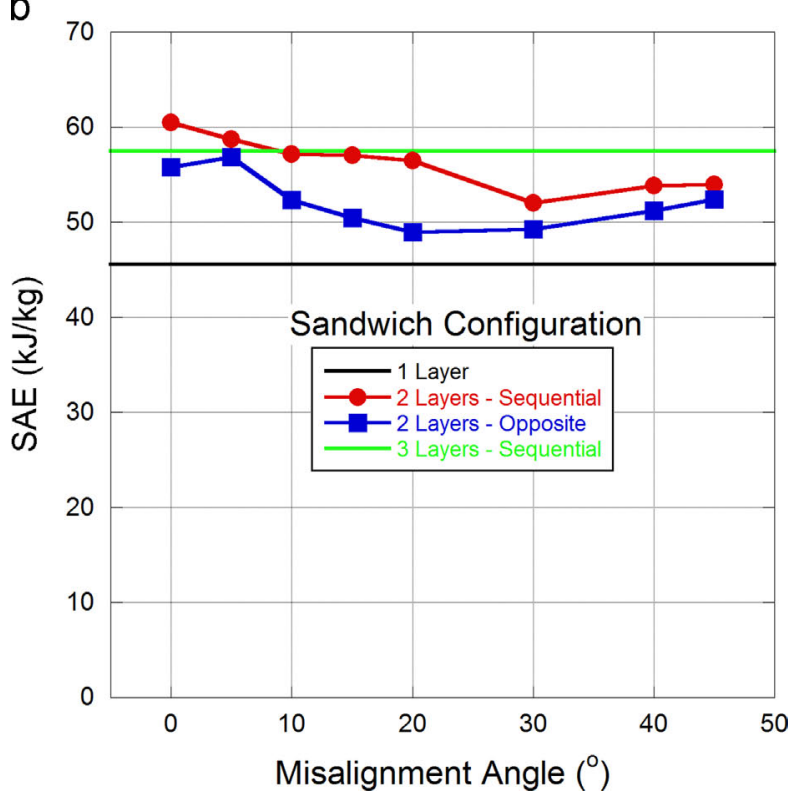

Fig. 14. (a) Misalignment angle, (b) SAE vs. Misalignment Angle.

deformation order change due to the relative position differences of constituents in different configurations. It is also interesting to note that rotation/misalignment between adjacent layers affects the results negatively except for $5^{\circ}$ rotation for opposite configurations. As misalignment angle increases, support provided by lower layer to the upper layer weakens. Therefore, upper layer tends to bend interlayer sheet as deformation progresses and a relatively asymmetric global deformation mode is observed, which results in decrease in absorbed energy. Another interesting result obtained by multilayering is that SAE values of sequential two layered sandwiches are higher than that of three layered sandwiches until nearly $20^{\circ}$ of misalignment. SAE values calculated for opposite two layered sandwiches are comparable with three layered configurations. Therefore, an optimum configuration could be chosen as sequential two layered sandwich with a maximum misalignment angle of $20^{\circ}$.

\section{Conclusions}

In this study, dynamic crushing and energy absorption of sandwich structures with combined geometry shells composing of a hemispherical cap and cylinder segment were investigated experimentally and numerically. Based on experimental and numerical observations the following conclusions can be reached:

- Peaks observed in quasi-static and low velocity results corresponding to buckling of constituents of core structures was followed by load drops due to overcoming buckling load and those showed lateral motion of plastic hinges with lower loads.

- The unit core structures placed in the middle of the specimens was squeezed between circumferential specimens and therefore their lateral motion was prevented.

- Higher buckling loads at lower deformation were observed for both constituents of core structures in confined quasi-static crushing due to additional lateral support and friction provided by confinement wall.

- In drop weight results, except for the shift in the deformation value, result was nearly the same with free quasi-static crushing result. Deformation of the structure started with a typical inward dimpling formation which is asymmetric due to the interaction between adjacent core units.

- For both unconfined and confined cases direct impact test results showed similar behavior except for that in confined test same initial striker speed cannot achieve to deform sandwich until its densification and an unloading/rebound stage was observed.

- Average forces obtained in direct impact experiments were higher than that of quasi-static and low velocity experiments due to inertial effect arising from higher impact velocity.

- Numerical simulations were achieved to represent the crushing behavior with a little difference which can be attained to amplification of effect of small difference between thickness variations of real and numerical specimens; therefore material properties and fold thicknesses.

- Flattening effect of confinement walls was observed for confined experiments and simulation results.

- For both unconfined and confined configurations, effect of inertia was more prominent comparing the effect of strain rate especially at higher impact velocities. Increase due to strain rate effect was nearly independent from impact velocity. Inertial effects in confined and unconfined configurations were parallel with a common offset due to the effect of confinement at all velocities. At high impact velocities effect of strain rate became almost independent from confinement effect.

- The lowest mean crushing force was calculated for single layer sandwich and the highest was calculated for sequential two layer sandwich.

- All multilayered configurations absorbed more energy than single layer sandwich. Nearly all of the sequential configurations have higher SAE values than opposite configurations independently from misalignment angle.

- Rotation / misalignment between adjacent layers affected results negatively except for $5^{\circ}$ rotation for opposite configurations. As misalignment angle increased, support provided by lower layer to the upper layer weakened, absorbed energy decreased. An optimum sandwich, comparing with other investigated ones, can be chosen as sequential two layered sandwich with a maximum misalignment angle of $20^{\circ}$.

\section{Acknowledgement}

The authors would like to thank the Scientific and Technical Council of Turkey (TUBITAK) for the Grant no. 112M141 and Prof. Dr. Mustafa Güden for his contributions. 


\section{References}

[1] Tan ZH, Luo HH, Long WG, Han X. Dynamic response of clamped sandwich beam with aluminium alloy foam core subjected to impact loading. Compos Part B-Eng 2013;46:39-45.

[2] Yu JL, Wang X, Wei ZG, Wang EH. Deformation and failure mechanism of dynamically loaded sandwich beams with aluminum-foam core. Int J Impact Eng 2003;28:331-47.

[3] Jing L, Wang Z, Ning J, Zhao L. The dynamic response of sandwich beams with open-cell metal foam cores. Compos Part B-Eng 2011;42:1-10.

[4] Li W, Huang G, Bai Y, Dong Y, Feng S. Dynamic response of spherical sandwich shells with metallic foam core under external air blast loading - numerical simulation. Compos Struct 2014;116:612-25.

[5] Liu XR, Tian XG, Lu TJ, Liang B. Sandwich plates with functionally graded metallic foam cores subjected to air blast loading. Int J Mech Sci 2014;84:61-72.

[6] Liu H, Cao ZK, Yao GC, Luo H], Zu GY. Performance of aluminum foam-steel panel sandwich composites subjected to blast loading. Mater Des 2013:47:483-8.

[7] Barnes AT, Ravi-Chandar K, Kyriakides S, Gaitanaros S. Dynamic crushing of aluminum foams: Part I - experiments. Int J Solids Struct 2014;51:1631-45.

[8] Kılıçaslan C, Güden M, Odacı İK, Tașdemirci A. Experimental and numerical studies on the quasi-static and dynamic crushing responses of multi-layer trapezoidal aluminum corrugated sandwiches. Thin Wall Struct 2014;78:70-8.

[9] Zhang L, Hebert R, Wright JT, Shukla A, Kim J-H. Dynamic response of corrugated sandwich steel plates with graded cores. Int J Impact Eng 2014;65:185-94.

[10] Li X, Wang Z, Zhu F, Wu G, Zhao L. Response of aluminium corrugated sandwich panels under air blast loadings: experiment and numerical simulation. Int J Impact Eng 2014;65:79-88.

[11] Yazici M, Wright J, Bertin D, Shukla A. Experimental and numerical study of foam filled corrugated core steel sandwich structures subjected to blast loading. Compos Struct 2014;110:98-109.

[12] Chi Y, Langdon GS, Nurick GN. The influence of core height and face plate thickness on the response of honeycomb sandwich panels subjected to blast loading. Mater Des 2010;31:1887-99.

[13] Nurick GN, Langdon GS, Chi Y, Jacob N. Behaviour of sandwich panels subjected to intense air blast - Part 1: experiments. Compos Struct 2009;91:433-41.

[14] Zhu F, Zhao L, Lu G, Wang Z. Deformation and failure of blast-loaded metallic sandwich panels - experimental investigations. Int J Impact Eng 2008;35:937-51.

[15] Crupi V, Epasto G, Guglielmino E. Collapse modes in aluminium honeycomb sandwich panels under bending and impact loading. Int J Impact Eng 2012;43:6-15.
[16] Foo CC, Seah LK, Chai GB. Low-velocity impact failure of aluminium honeycomb sandwich panels. Compos Struct 2008:85:20-8.

[17] Othman AR, Barton DC. Failure initiation and propagation characteristics of honeycomb sandwich composites. Compos Struct 2008;85:126-38.

[18] Lee S, Barthelat F, Hutchinson JW, Espinosa HD. Dynamic failure of metallic pyramidal truss core materials - experiments and modeling. Int J Plast 2006;22:2118-45.

[19] Tasdemirci A, Sahin S, Kara A, Turan K. Crushing and energy absorption characteristics of combined geometry shells at quasi-static and dynamic strain rates: experimental and numerical study. Thin Wall Struct 2015;86:83-93.

[20] Palanivelu S, Van Paepegem W, Degrieck J, De Pauw S, Vantomme J, Wastiels J et al. Low velocity axial impact crushing performance of empty recyclable metal beverage cans. Int J Impact Eng 2011;38:622-36.

[21] Palanivelu S, Van Paepegem W, Degrieck J, Reymen B, Ndambi J-M, Vantomme J, et al. Close-range blast loading on empty recyclable metal beverage cans for use in sacrificial cladding structure. Eng Struct 2011;33:1966-87.

[22] Ghamarian A, Abadi MT. Axial crushing analysis of end-capped circular tubes. Thin Wall Struct 2011;49:743-52.

[23] Gupta PK. Axial compression of tubular metallic shells having combined tubefrusta geometry, In: Proceedings of the international conference on structural engineering, construction and management, ICSECM, Sri Lanka; 2011.

[24] Shojaeefard MH, Najibi A, Anbarloei M, Yeganeh M. Experimental and numerical crashworthiness investigation of combined circular and square sections. J Mech Sci Technol 2014;28:999-1006.

[25] Kılıçaslan C, Odacı İK, Taşdemirci A, Güden M. Experimental testing and full and homogenized numerical models of the low velocity and dynamic deformation of the trapezoidal aluminium corrugated core sandwich. Strain 2014;50:236-49.

[26] Wilbert A, Jang WY, Kyriakides S, Floccari JF. Buckling and progressive crushing of laterally loaded honeycomb. Int J Solids Struct 2011;48:803-16.

[27] Al Galib D, Limam A. Experimental and numerical investigation of static and dynamic axial crushing of circular aluminum tubes. Thin Wall Struct 2004;42:1103-37.

[28] Calladine CR, English RW. Strain-rate and inertia effects in the collapse of two types of energy-absorbing structure. Int J Mech Sci 1984;26:689-701.

[29] Zhang TG, Yu TX. A note on a 'velocity sensitive' energy-absorbing structure. Int J Impact Eng 1989;8:43-51.

[30] Tam LL, Calladine CR. Inertia and strain-rate effects in a simple plate-structure under impact loading. Int J Impact Eng 1991;11:349-77. 